\title{
MEMS-BASED OSCILLATORS: A REVIEW
}

\author{
JAMILAH KARIM ${ }^{1,2}$, A.H.M. ZAHIRUL ALAM ${ }^{1}$ AND ANIS NURASHIKIN NORDIN ${ }^{1}$ \\ ${ }^{I}$ Electrical and Computer Engineering Department, Faculty of Engineering, \\ International Islamic University Malaysia, \\ PO Box 10, 50728, Kuala Lumpur, Malaysia. \\ ${ }^{2}$ Electrical Engineering Faculty, University Technology MARA, \\ 40450, Shah Alam, Selangor, Malaysia.
}

jamilah_karim@yahoo.com,anisnn@gmail.com

\begin{abstract}
This paper presents an overview of micro electromechanical (MEMS) based oscillators. The accuracy and stability of the reference frequency will normally limit the performance of most wireless communication systems. MEMS technology is the technology of choice due to its compatibility to silicon, leading to integration with circuits and lowering power consumption. MEMS based oscillators also provide the potential of a fully integrated transceiver. The most commonly used topology for MEMS based oscillators are pierced oscillator circuit topology and TIA circuit topology. Both topologies result in very competitive output in terms of phase noise and power consumption. They can be used for either higher or lower Rx. The major difference between both topologies is the number of transistors used. TIA circuit used number of transistors comparatively to pierce circuit. Thus the design complexity of the TIA is higher. Pierce circuit is simpler, provide straightforward biasing and easier to design. The highly integratable MEMS-based oscillators have made them much needed in future multiband wireless system. Hence, the future wireless systems will be able to function globally without facing difficulties.
\end{abstract}

ABSTRAK: Kertas kerja ini membentangkan gambaran keseluruhan mikroelektromekanikal (MEMS) berdasarkan pengayun. Ketepatan dan kestabilan frekuensi rujukan sering membataskan perlaksanaan kebanyakan sistem komunikasi tanpa wayar. Teknologi MEMS merupakan teknologi pilihan memandangkan ia serasi dengan silikon; membolehkan integrasi dengan litar dan penggunaan tenaga yang rendah. Pengayun berdasarkan MEMS juga berpotensi sebagai integrasi penuh penghantarterima. Topologi yang sering digunakan untuk pengayun berdasarkan MEMS adalah topologi litar pengayun pencantas dan topologi litar TIA. Keputusan bagi kedua-dua topologi adalah amat kompetitif dari segi fasa bunyi dan penggunaan tenaga. Ia boleh digunakan untuk meninggikan atau merendahkan $\mathrm{R}_{\mathrm{x}}$. Perbezaan utama di antara keduadua topologi adalah bilangan transistor yang digunakan. Litar TIA menggunakan bilangan transistor yang lebih daripada litar pencantas. Maka, rekaan TIA adalah lebih rumit. Litar pencantas adalah lebih ringkas, memberikan pincangan yang jelas dan rekabentuk yang mudah. Pengayun berdasarkan MEMS amat bersepadu menjadikan ia sesuai sebagai sistem tanpa wayar berbilang jalur masa depan. Jesteru sistem tanpa wayar dapat berfungsi pada peringkat global tanpa sebarang kesulitan..

KEYWORDS: CMOS oscillator; MEMS based oscillator; MEMS SAW resonator

\section{INTRODUCTION}

The increasing demand for portable, small-sized, personal wireless consumer devices, wireless sensor nodes coupled with emerging field of radio-frequency micro-electromechanical systems (RF-MEMS) has fueled exciting research on the complete integration 
of wireless transceivers [1]. Recent advancement of silicon based radio-frequency (RF) electronics have driven the innovation of Complementary Metal Oxcide Semiconductor (CMOS)-based, low-cost, high technology and portable consumer devices. The escalating need for wireless circuits to be portable has highlighted the importance of low-power consumption to enable long operating lifetimes for such circuits [2]. Traditionally, bipolar RF-front ends have shown low current consumption compared to their CMOS counterparts, especially for cellular applications which has complex network environments [3]. Recent technological developments in fabrication of CMOS have led to a marked improvement in the performance of CMOS devices in the RF range [4-7]. The increased capabilities of these CMOS devices have led to the successful design and implementation of major RF transceiver building blocks such as low-noise amplifiers (LNAs), power amplifiers, mixers and local oscillators (LOs) [8-12]. Silicon-based RF front ends have been successfully implemented in [13] and [14]. Competitive low-power CMOS RF-front end transceivers, which have comparable performance to their Bipolar Junction Transistor (BJT) counterparts have been described in [3].

To date, the major hurdle in achieving a completely silicon based heterodyning transceiver is the off-chip resonators, which typically does not have integrated circuit (IC) compatible fabrication methods [15]. A key component in the transceiver system, these resonators are often utilized for frequency selection in the radio-frequency (RF) and intermediate-frequency (IF) stages. Micro-Electro-Mechanical-Systems (MEMS) show promising prospects to meet all these demands. Although typically optimized for integrated circuits, a wide variety of novel MEMS devices have been successfully implemented using CMOS fabrication techniques[16-19]. Recent advances in the ICcompatible micromachining technologies, yield microscale silicon based resonators that have brought us a step nearer towards achieving the ultimate objective of a single-chip transceiver [20]. Complete integration of the resonators with the RF circuits using the same CMOS fabrication process eliminates the need for lossy wire-bonds to connect the passive device to the circuits, reducing the parasitics, attenuation and thus improving the performance of the system.

Modern wireless transceiver circuits can be categorized into either analog frontend circuits or digital baseband circuits. Figure 1 illustrates a typical RF front end receiver circuit. Mixers with appropriate local oscillators typically perform frequency translation as required by the transceiver during signal transmission and reception. The challenge here is to design oscillators that meet the strict requirements imposed by different wireless standards. For example, GSM itself has four communication bands, which are $850 \mathrm{MHz} / 900 \mathrm{MHz}$ and $1800 \mathrm{MHz} / \mathrm{DCS} 1900 \mathrm{MHz}$. The new IEEE 802.11a standard WLAN operates at 5.15 to $5.35 \mathrm{GHz}$ and 5.725 to $5.875 \mathrm{GHz}$ bands, with maximum data rates of $54 \mathrm{Mbps}$. Bluetooth on the other hand, operates at frequencies ranging from 2.4 to $2.4835 \mathrm{GHz}$ with data rates of $720 \mathrm{Kbps}$. On top of this are the general requirements for oscillators to be low cost, have low-power consumption, small in size, multi-band (tunability) capabilities and siliconcompatible. This results in large chip area and high power requirement to allow multi-band/mode function. Area optimization and maximum block reusability for multiple mode of operation are the main challenges for System-on-Chip wireless transceiver designs [21]. 


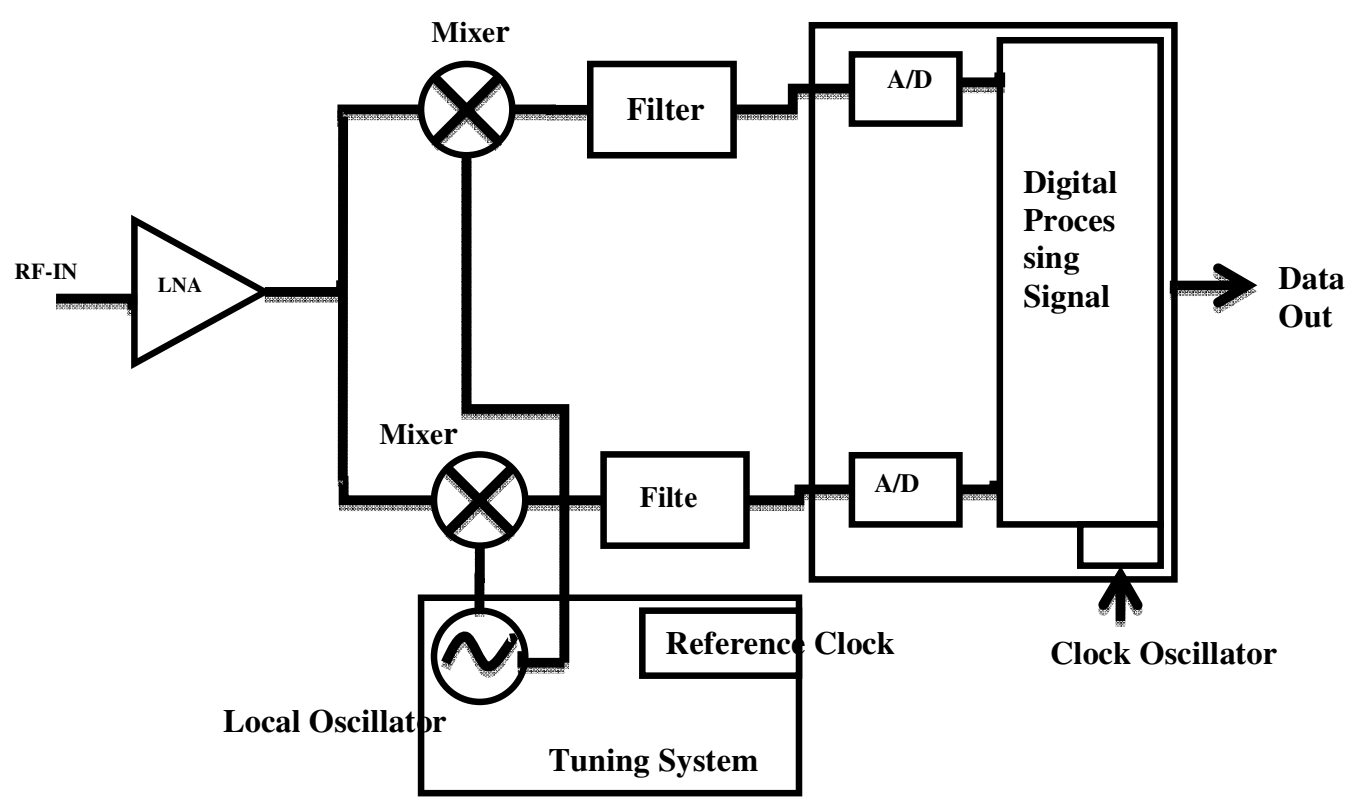

Fig. 1: Block diagram of possible application of oscillator in receiver.

\section{OSCILLATOR}

\subsection{An Overview}

The most important part in transceiver and other electronic applications is the oscillator. Figure 1 shows possible application of oscillator in a receiver circuit. The oscillator will provide reference signal or clock signal to facilitate the system synchronization, signal modulation and timing. It is important for the oscillator to produce the clean, smooth and stable output signal with clear frequency spectrum without any input. A pure sinusoidal signal is described in Eqn (1), and it is generated from no input signal other than the dc bias. An ideal oscillator has an ideal output,

$$
V_{\text {out }}=A \cos \left(\omega_{\text {ost }} t\right)
$$

where $A$ is the oscillation amplitude, $\omega_{\text {ost }}$ is the oscillating frequency and $V_{\text {out }}$ is the oscillation output voltage.

Ideally, all signal power is located at the oscillating frequency, $\omega_{o s c}$. Unfortunately, in practice it is not possible to generate a noise free signal at a specific frequency. Real oscillator outputs are accompanied by unwanted harmonics. Carrier power is now distributed over the carrier frequency's bandwidth and its harmonics, leading to power reduction at the wanted frequency.

Besides the harmonics, practical oscillators also suffer from phase noise sidebands or jitter in time domain. To incorporate phase noise and jitter, the output signal of practical oscillator can be written as

$$
V_{\text {out }}=\operatorname{Acos}\left(\omega_{\text {osc }} t+\theta\right)
$$

where $\theta$ is stochastic variable presenting the phase uncertainty due to the presence of jitter. 
To generate a pure sinusoidal signal from noise, oscillators employ feedback systems. Figure 2 illustrates a conventional oscillator block diagram which consists of a positive feedback amplifier $A_{v}(j \omega)$, a frequency-determining network $\beta(j \omega)$ and the noise input $v_{i}$.

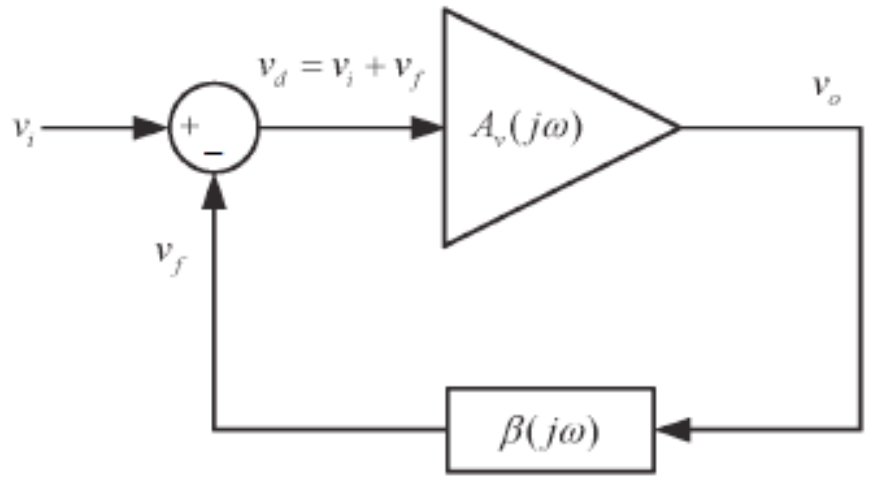

Fig. 2: Block diagram of feedback system.

The input voltage, $v_{i}$ and the output voltage, $v_{o}$ can be related as follows:

$v_{o}=\frac{A_{v}(j \omega)}{1-\beta(j \omega) A_{v}(j \omega)} v_{i}$

where, $A_{v}(j \omega), \beta(j \omega)$ are the amplifier gain and feedback transfer functions respectively. $A_{v}(j \omega) \beta(j \omega)$ is known as the loop gain. From this relation it is possible to derive the close loop gain $\left[A_{v}(j \omega)\right]$ of the feedback system as follows

$$
A_{v f}(j \omega)=\frac{v_{o}}{v_{i}}=\frac{A_{v}(j \omega)}{1-\beta(j \omega) A_{v}(j \omega)}
$$

To achieve oscillation from the feedback system (finite $v_{o}$ ) the denominator of Eqn (4) has to be zero. The loop gain, $\beta(j \omega) A_{v}(j \omega)$ must be unity. This relation is known as the Barkhausen criterion.

$1-\beta(j \omega) A_{v}(j \omega)=0$

$\beta(j \omega) A_{v}(j \omega)=1$

This relation can be expressed in polar form as follows:

$\left|\beta(j \omega) A_{v}\left(j \omega^{\prime}\right)\right| \angle\left(\beta(j \omega) A_{v}\left(j \omega^{\prime}\right)\right)=1$

Hence,

$\left|\beta(j \omega) A_{v}\left(j \omega^{\prime}\right)\right|=1$

and $\angle\left(\beta(j \omega) A_{v}\left(j \omega^{\prime}\right)\right)= \pm n 360^{\circ}$

where $\mathrm{n}=0,1,2,3$.

The above mentioned condition implies that any feedback system with unity loop gain and phase shift of $\pm n 360$ can oscillate. To achieve oscillation, the Barkhausen criterion is necessary but not sufficient [22]. To ensure oscillation in the presence of temperature and process variation the loop gain has to be chosen at least twice or three times the required value [23].

In any transceiver system, it is vital that the oscillators autonomously start oscillating, usually triggered by noise, when the system is switched on. To guarantee oscillator start- 
up, the open loop gain must initially be larger than unity. This requirement is called the "start-up condition": $\left|\beta(j \omega) A_{v}\left(j \omega^{\prime}\right)\right|>1$ and the open loop gain ranges typically from 2 to 5 for self-limiting oscillators to ensure start-up.

\subsection{Types of Oscillators}

There are two types of frequency generating and timing devices technologies that exist today, namely mechanical oscillators and electrical oscillators [24]. Each technology will normally cater for specific application. The frequency of mechanical oscillators are dominated by quartz resonator or bulk piezoelectric resonator. The frequency of electrical oscillators are controlled by the R-C or L-C circuit. Electrical oscillators can be fabricated using CMOS process. However it cannot rival the performance of mechanical oscillators. Unfortunately, conventional mechanical oscillators are bulky and cannot be integrated on silicon. It can only be fabricated on piezoelectric substrates. Figure 3(a) shows the quartz oscillator.

\subsubsection{Mechanical Oscillator}

The piezoelectric substrate is the main component for device to function as a resonator. Mechanical resonators are made either from quartz or state of the art MEMSbased resonators. A quartz resonator is produced by cutting the crystal at a.certain specific angle and various axes. This cutting point will determine the electrical and physical parameter of quartz crystals. Figure 3(b) shows the typical cut of quartz crystals. MEMSbased resonators can be categorized into two major parts; i) Electrostatic based resonators and ii) Piezoelectric based resonators. The MEMS based resonators are made from electrod, anchors or beam which is designed using metal layers inherent in the CMOS technology process. When the voltage is applied to a mechanical resonator, it will vibrate and produce the steady signal or the frequency. The frequency produced depends on the cut, size and shape of the crystal resonator or the electrode of the MEMS based resonator.

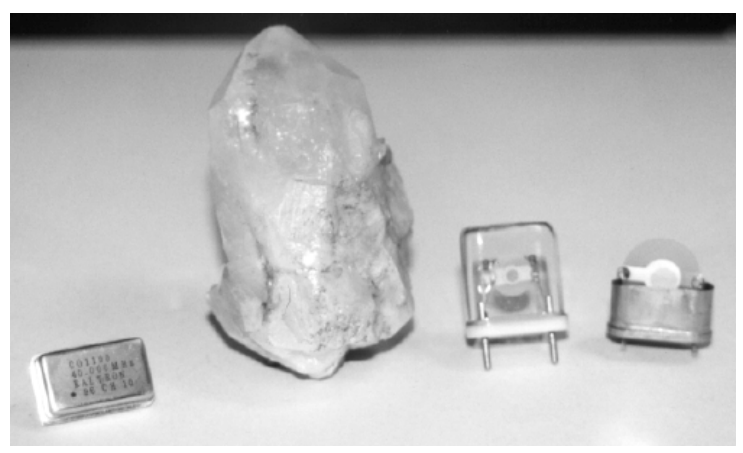

(a)

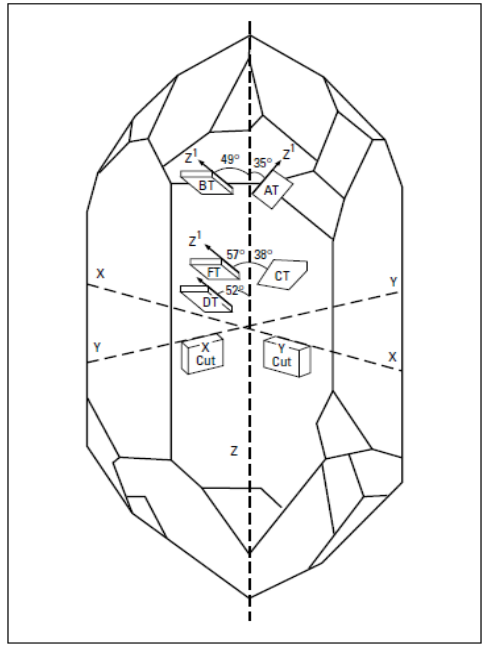

(b)

Fig. 3: (a) Left to right: Raltron $40 \mathrm{MHz}$; a natural quartz crystal (South Dakota); Phillips $27 \mathrm{MHz}$; a cutaway view of a typical crystal oscillator (http://materials.usask.ca/photos/),

(b) Typical crystal cut [25]. 


\subsubsection{Electrical Oscillator}

Electrical oscillators can be classified based on their frequency-selecting component into two basic categories namely; LC and RC oscillators. LC oscillators are constructed using an inductor and a capacitor which preserves the energy during the oscillation period. As its name suggests, an RC oscillator circuit consists of a capacitor and a resistor. The usage of a resistor instead of an inductor as a frequency selecting component does not allow energy to be preserved during the oscillation period, leading to poor spectral purity [21]. Due to this, LC oscillators have superior noise performance compare to RC oscillators, making them more popular in RF transceivers. For certain high frequency applications however, the $\mathrm{RC}$ ring oscillator is still being considered due to their ease of integration and large tuning range.

\subsubsection{LC Oscillator}

LC oscillator can be classified into various topologies depending on the arrangement of the inductor and capacitor in LC oscillator circuit either in series or parallel [26]. Each type will have different output. The resonance frequency of purely parallel LC resonator is expressed as follows:

$$
f_{\text {osc }}=\frac{1}{2 \pi \sqrt{L_{S} C_{S}}}
$$

It is rarely possible to find a pure resonator circuit. In practice inductor tends to be lossier than the capacitor. So, it is practical to represent the inductor $\left(L_{S}\right)$ in series with a resistor $\left(R_{S}\right)$. For ease of understanding this tank circuit can be represented by equivalent a parallel circuit of resistor $\left(R_{p}\right)$, inductor $\left(L_{p}\right)$ and capacitor $\left(C_{p}\right)$, where $R_{p}$ and $L_{p}$ are given by the expression below:

$$
\begin{aligned}
& R_{p}=R_{S}\left(Q^{2}+1\right) \\
& L_{p}=L_{S}\left(\frac{Q^{2}+1}{Q^{2}}\right)
\end{aligned}
$$

where, $Q=\frac{2 \pi f L_{p}}{R_{p}}=\frac{2 \pi f L_{S}}{R_{S}}$. In practice it is desirable to have higher value of quality factor, $Q$. In this case $R_{p} \approx R_{S} Q^{2}$ and $L_{p} \approx L_{S}$. At resonance frequency, the tank network would become simply a resistor i.e. the phase difference between voltage and current drops to zero. Impedance of the tank becomes inductive when $\omega<\omega_{\text {osc }}$ and turns capacitive when $\omega>\omega_{\text {osc }}$. Oscillation of the tank would be damped due to the presence of the lossy element, $R_{p}$. In order to sustain the oscillation this resistance $\left(R_{p}\right)$ has to be nullified. This is done by adding active element with this tank.

L-C tank and an active device may constitute an L-C oscillator. For simplicity we may consider transistor as the active device. The tank is placed at the collector and the feedback signal is fed to the base or the emitter. Common emitter connection is preferred in order to achieve zero phase angle between the current and the voltage. The direct connection from the collector to emitter would reduce the $\mathrm{Q}$ of the coil, drop the loop gain below unity and prevent oscillation. This is because resistive loading, $\frac{1}{g_{m}}$ is seen at the emitter. Due to this, impedance transformation to a higher value would be required from 
the tank to the emitter. The capacitive and inductive divider is more commonly used in oscillator application. They are known as Colpitts and Hartley configuration. The configuration in Fig. 4(a) is Colpitts and Fig. 4(b) is Hartley. Inductor has very low Q than its counterpart capacitor and take large area in the chip. So, Colpitts configuration is preferred over Hartley.
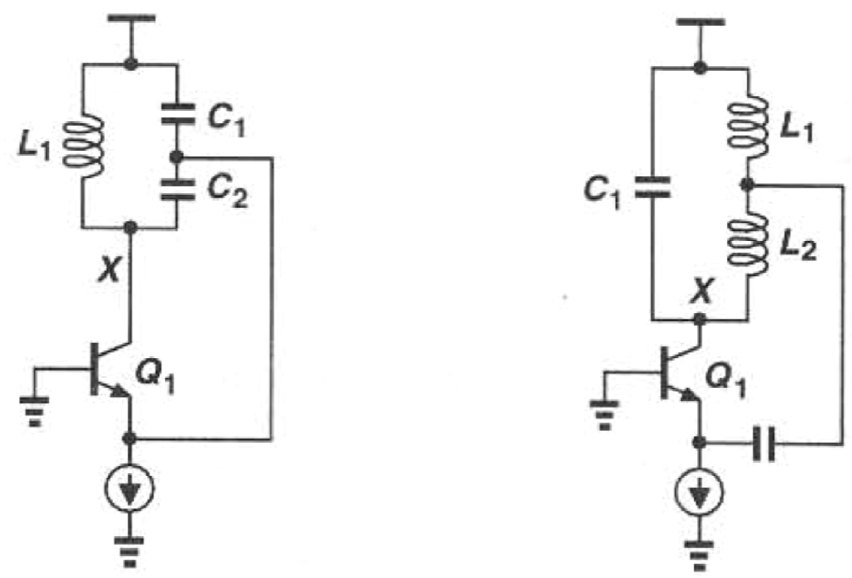

Fig. 4: Oscillator configuration (a) Colpitts (b) Hartley [26].

\subsubsection{RC Oscillator}

RC Oscillator produces an output signal using regenerative feedback from the resistor-capacitor combination. Figure 5 shows the RC feedback network. This network can be arranged to produce either leading phase shift or lagging phase shift. It will produce the same transient output. Varying the capacitor or the resistor in RC network will vary the resonance frequency produce. If all the resistors, $\mathrm{R}$ and the capacitors, $\mathrm{C}$ in the phase shift network are equal in value, then the frequency of oscillations produced by the RC oscillator is given as:

$$
f_{r}=\frac{1}{2 \pi R C \sqrt{2 N}}
$$

$\mathrm{N}$ is the number of RC stages.

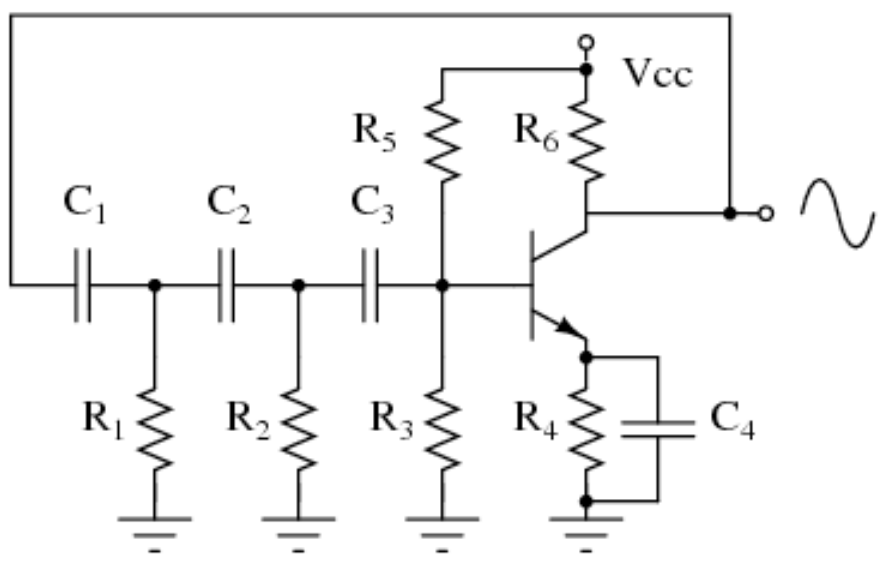

Fig. 5: RC oscillator with BJT sustaining circuit (http://www.allaboutcircuits.com/vol_3/chpt_9/4.html). 
The advantage of $\mathrm{RC}$ oscillator is the ability to provide constant oscillation frequency even with varying loads. Furthermore the stability of this kind of oscillator can be easily improved by increasing number of cascading stages. However, the limitations of these oscillators are that they can be only used for lower frequency applications since the phase noise increase with the increasing number of stages [27].

\subsection{MEMS-Based Oscillators}

\subsubsection{Why MEMS-Based Oscillator}

The growth and demand for the wireless product to be portable, light weight, consume less power and easy to handle has fuelled research on a fully integrated transceiver. MEMS technology allows the miniaturizations of the mechanical oscillators to micro/nano scales. These MEMS based oscillators provide a promising solution for applications where size and degree of integration are crucial. As the devices become small and are all integrated on the same chip, the power consumed will also be less.

The frequency selector for MEMS based oscillators is the MEMS resonator. The performance of the resonators is measured based on their $\mathrm{Q}$ factors. The higher the $\mathrm{Q}$, the better the signal received by the transceiver. As reported in [28], current MEMS resonator has shown great performance with measured Q factors $>1000$ and can operated in $\mathrm{GHz}$ frequency range.

\subsubsection{Previous Work on MEMS-Based Oscillator}

A film bulk acoustic wave resonator (FBAR) was used in an oscillator design shown in [29]. The frequency of this resonator is determined by the film thickness [30]. This oscillator has a differential oscillator circuit topology and couples with two symmetrical oscillator cores for quadrature signal generation. The cross coupled transistor pair provides high output resistance. Figure 6 shows the Bulk acoustic wave (BAW) differential circuit topology. The topology is normally used for relatively high parallel resonant frequency which require output resistance to be higher than the motional resistance $R_{x}$ [31]. The advantage of this topology is its capability to produce higher amplitude swings and better supply rejection. The device was realized using $0.13 \mu \mathrm{m}$ CMOS process. This oscillator operates at $2.1 \mathrm{GHz}$, consumes $0.6 \mathrm{~mW}$ power and has phase noise of $143.5 \mathrm{dBc} / \mathrm{Hz}$ at 1 MHz. The combination of high $\mathrm{Q}$ mechanical resonator with quadrature coupling technique lessens the oscillator power and phase noise. However, since the resonant frequency of the FBAR is determined by the film thickness, therefore for different resonant frequency requires different process and impossible they can be fabricated on the same chip. Thus several resonators with different operating frequency have to be put on a single oscillator chip if this is to be used for a system with multiple standards. It is expected that this chip will be more cost effective than buying numbers of single FBAR oscillator [32].

A multi-frequency oscillator circuit based on piezoelectric AlN contour mode MEMS resonator was introduced in [33]. The use of contour mode allows arrays of piezoelectric MEMS resonator with different frequencies to be fabricated on the same substrate [34]. The centre frequency of this resonator is determined by lithographic techniques. This oscillator uses a pierce circuit as its sustaining circuit. The topology is very reliable, stable and mostly used for quartz crystal oscillators. The circuit consist of only a single transistor and is designed to work with multiple resonators with different operating frequencies. Biasing current for $\mathrm{C}_{1}$ and $\mathrm{C}_{2}$ in Fig. 7 is proportional to their size, subsequently to the power consumed. Thus to minimize the power consumed in this topology, no additional parasitics were added. The oscillators achieved operating frequencies of 176, 222, 307 and 
$482 \mathrm{MHz}$, phase noise value between $-88 \sim-68 \mathrm{dBc} / \mathrm{Hz}$ at $1 \mathrm{kHz}$ offset and consume 10 $\mathrm{mW}$ power. The CMOS technology used to realize the oscillator circuit is $5 \mathrm{~V}$, AMI Semiconductor $0.5 \mu \mathrm{m}$ process. The resonator's Q factor varies from 1000-4000 and motional resistance varies from 25-1000 $\Omega$. Low motional resistance of the resonator (or high $\mathrm{Q}$ factors) allows it to be easily interfaced with the conventional electronic devices without the need for matching network or special circuits.

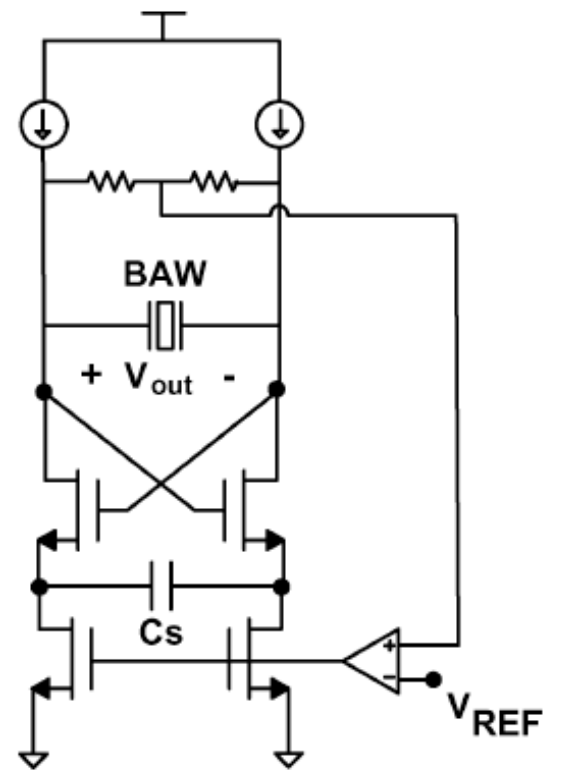

Fig. 6: BAW Differential Voltage Control Oscillator [29].

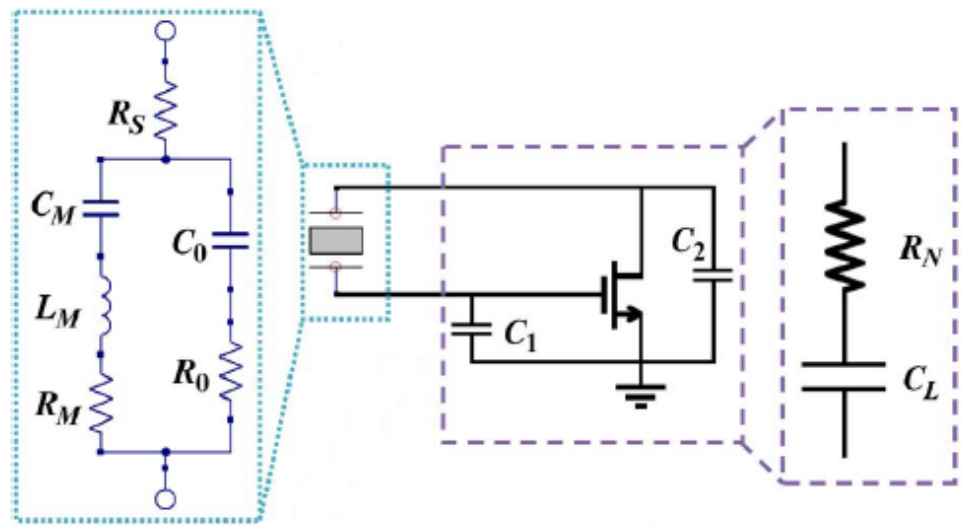

Fig. 7: Pierce oscillator circuit topology for AlN contour mode MEMS resonator [33].

In [35], authors have demonstrated switchless dual mode oscillator based on a single piezoelectric AIN MEMS resonator. Two different frequencies are generated by a single piezoelectric AlN MEMS resonator which has two different Lamb-wave modes of vibration. The resonator's Q factor is 1800 and 600 at $472 \mathrm{MHz}$ and $1.94 \mathrm{GHz}$ resonance frequencies respectively. The Pierce oscillator circuit topology was used in the design. The topology consists of three transistors as shown in Fig 8. Transistors $\mathbf{M}_{1}$ and $\mathbf{M}_{2}$ are the core amplifier circuit. Transistor $\mathrm{M}_{3}$ is always turned on and provides a large resistor to bias the drain voltage and gate of $\mathrm{M}_{1}$ and $\mathrm{M}_{2}$. The dual mode operation is realized by tuning the supply voltage $\mathrm{V}_{\mathrm{S} 1}$ of the pierce circuit topology. The advantage of this 
topology is its capability to reduce the load on the resonator. The tuneable oscillator circuit design was implemented using $0.5 \mu \mathrm{m}$ ON Semiconductor CMOS process. The oscillator has shown good performance when operated at both frequencies; with measured phase noise for $472 \mathrm{MHz}$ is $-82 \mathrm{dBc} / \mathrm{Hz}$ at $1 \mathrm{kHz}$ offset frequency and for $1.94 \mathrm{GHz}$ frequency is $-153 \mathrm{dBc} / \mathrm{Hz}$ at $1 \mathrm{MHz}$ offset frequency. The advantage of this design is it can reduce the switching time required to change from one frequency to another. However, to ensure more than one resonant mode is excited and detected by the same electrodes, the bottom and top electrode of the resonator must be designed appropriately.

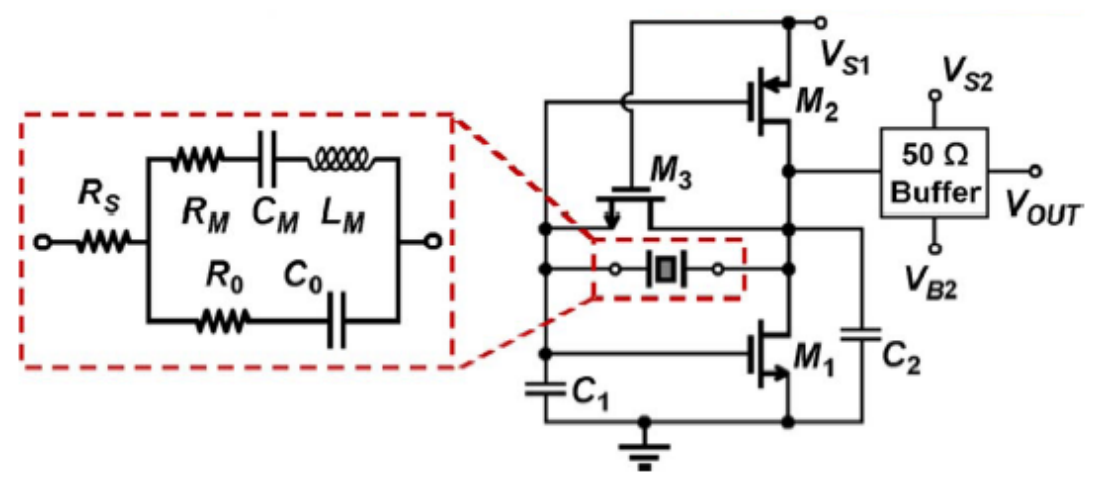

Fig. 8: Pierce oscillator circuit topology for Dual Mode AlN MEMS resonator [35].

Pierce oscillator circuit topology with more transistors was introduced by[36]. The circuit consists of two stage amplifiers as shown in Fig. 9. The first stage is the front end buffer. The design is adopted from the unity gain amplifier. The amplifier generates very high trans-impedance gain, and is design to minimize the effect of parasitic capacitance. Second stage is the high gain voltage amplifier. This stage will provide an additional gain require to sustaining the oscillation. The cascode load is used to provide high impedance, thus produce higher bandwidth amplifier and larger phase shift at resonance frequency. The topology is used to sustain the oscillation from the cantilever MEMS resonator. The resonator yields very high $\mathrm{R}_{\mathrm{x}}=25.7 \mathrm{MHz}$ at $6.4 \mathrm{MHz}$ resonance frequency with $\mathrm{Q}=100$. The cantilever based oscillator generates $6.32 \mathrm{MHz}$ oscillation frequency. The phase noise performance is $-94.3 \mathrm{dBc} / \mathrm{Hz}$ at $100 \mathrm{kHz}$ offset frequency. The amplifier circuit is implemented using a $0.35 \mu \mathrm{m}$ CMOS process.
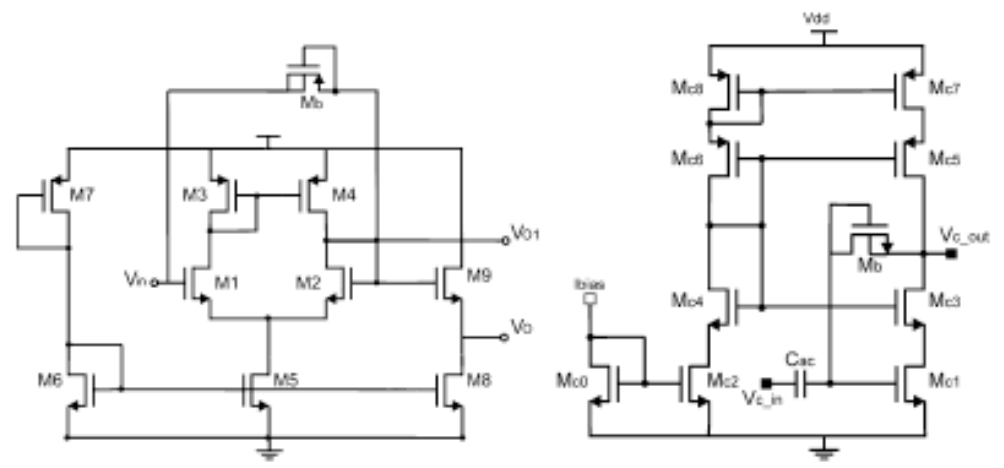

Fig. 9: Schematic circuit of two stage transimpedance amplifier. Front end buffer with output stage (on left), voltage amplifier with cascode load (on right) [36].

Figure 10 shows the CMOS MEMS oscillator circuit design based on I-shape bulk acoustic resonator (IBARs). The oscillator circuit consists of the IBARs, amplifier, level 
control and bias generator. The core circuit consist of two stage transimpedance amplifier (TIA) with self biased folded cascode transconductance amplifier [37]. The oscillation amplitude is limited by level control circuit, which generates control voltage to the gate of transistor $\mathrm{M}_{15}$. The amplifier achieved $175 \mathrm{MHz}$ bandwidth and consumes about $1.9 \mathrm{~mW}$ power with parabolic compensation method. The design is very complex with 5 blocks of circuit involved, thus increasing the chip area. The resonator achieved very high Q 100,000 at medium frequency range $1-30 \mathrm{MHz}$ and low motional resistance of $900 \Omega$. Resonator that are used in wireless application must have higher $\mathrm{Q}$ since higher $\mathrm{Q}$ resonators generate accurate, precise and stable oscillation frequencies [32]. The phase noise performance is $-90 \mathrm{dBc} / \mathrm{Hz}$ at $100 \mathrm{~Hz}$ offset and $-110 \mathrm{dBc} / \mathrm{Hz}$ at $1 \mathrm{kHz}$ offset. The oscillator is designed and fabricated using $0.5 \mu \mathrm{m}$ CMOS AMI Semiconductor. Although this oscillator has very high $\mathrm{Q}$, the oscillation frequency of this oscillator is still low compared to RF quartz crystal oscillator.

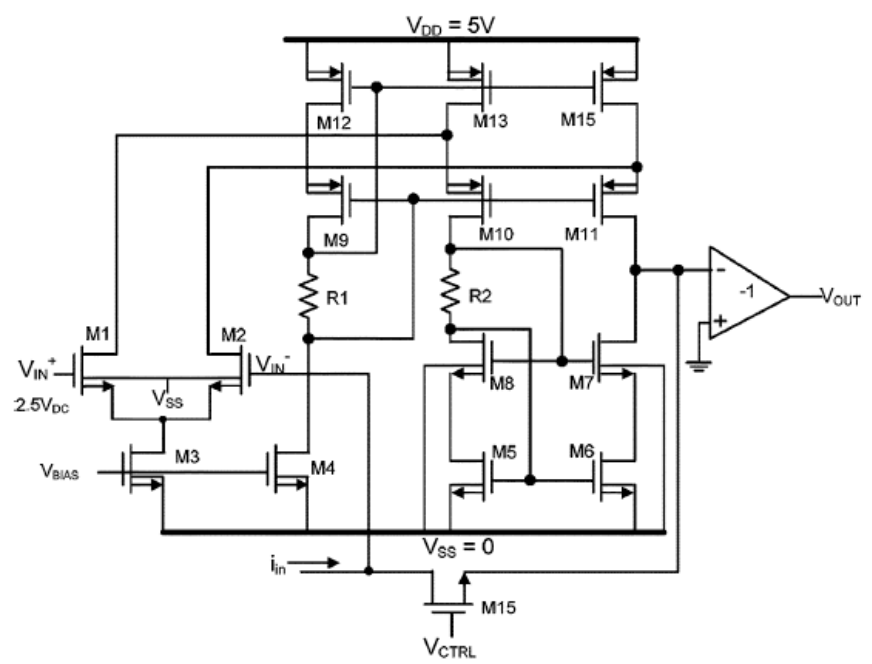

Fig. 10: Transimpedance amplifier circuit for IBARs MEMS resonator [38].

MEMS oscillators based on breathe -mode ring resonator is presented in[39]. This resonator is driven differentially and the signal is also sensed differentially at two terminals as in Fig. 11(b). This design reduces the air damping which subsequently increases the $\mathrm{Q}$ factor. The resonator resonates at $19.84 \mathrm{MHz}$ with $\mathrm{Q}=160,000$ and $\mathrm{R}_{\mathrm{x}}=$ $65 \mathrm{k} \Omega$. The resonator is wire bonded with TIA circuit in order to sustain the oscillation. This amplifier circuit was implemented using $0.35 \mu \mathrm{m}$ CMOS technology. The transimpedance amplifier circuit used consists of the operational transimpedance amplifier (OTA). The OTA is realized as a single stage, cascode, common source amplifier. The NMOS variable capacitors are used for gain tuning. The transimpedance amplifier gain is tunable in the range of $12 \mathrm{k} \Omega$ to $69 \mathrm{k} \Omega$. The performance achieved is as follows: oscillation frequency $=20 \mathrm{MHz}$, phase noise floor $=-131 \mathrm{dBc} / \mathrm{Hz}$ and power consumed $=$ $6.9 \mathrm{~mW}$.

The sustaining circuit introduced in [40] consist of TIA, series tuning circuit and negative capacitor or active inductor cancellation circuit. Detailed circuit diagram for both cases are shown in Fig. 12. The topology introduced here is almost the same with authors" previous work in [41], except that this design has an extra stage of inverter with tunable shunt-shunt feedback and also the series capacitor tuning circuit. The series capacitor tuning circuit is used to electronically tuning the oscillation frequency. Even though this 
method is the most effective method to tune the resonator frequency, the existence of parasitic capacitance will reduce the variation of the tuning element. Therefore the parasitic capacitance cancellation circuit is necessary. The inverter amplifier with tunable shunt-shunt feedback was used to allow the conversion of low noise current to voltage. This stage was made tunable to allow the phase noise optimization. The amplifier circuit was tested with two different resonance frequencies LBAR. The characteristics of these LBARs are: $\operatorname{LBAR}(1) ; \mathrm{f}_{\mathrm{r}}=427 \mathrm{MHz}, \mathrm{R}_{\mathrm{x}}=180 \Omega$ and $\mathrm{Q}=1400$ and $\operatorname{LBAR}(2) ; \mathrm{f}_{\mathrm{r}}=541$ $\mathrm{MHz}, \mathrm{R}_{\mathrm{x}}=55 \Omega$ and $\mathrm{Q}=3000$. The tunable TIA was implemented using $0.18 \mu \mathrm{m}$ CMOS process. The amplifier circuit consume about $11.4 \mathrm{~mW}$ power. The phase noise performance for $427 \mathrm{MHz}$ and $541 \mathrm{MHz}$ oscillator circuit with negative capacitance calcellation are $-82 \mathrm{dBc} / \mathrm{Hz}$ and $-86 \mathrm{dBc} / \mathrm{Hz}$ at $1 \mathrm{kHz}$ offset frequency respectively.

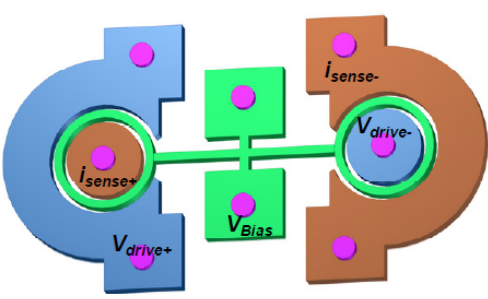

(a)

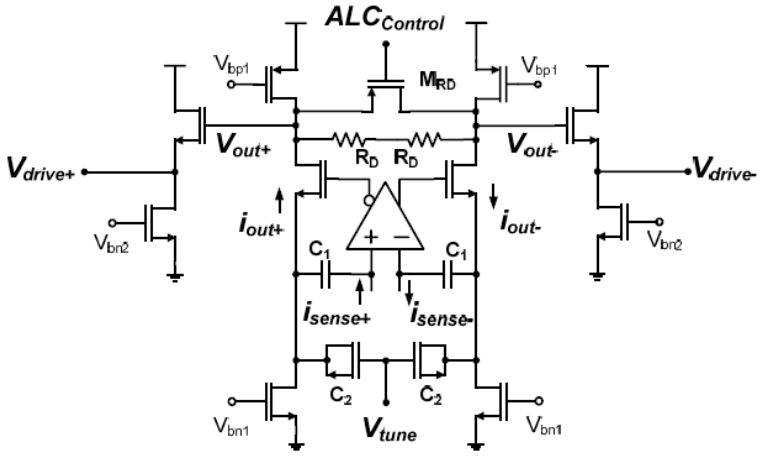

(b)

Fig. 11: (a) Breathe mode ring resonator, (b) Differential transimpedance amplifier circuit [39].
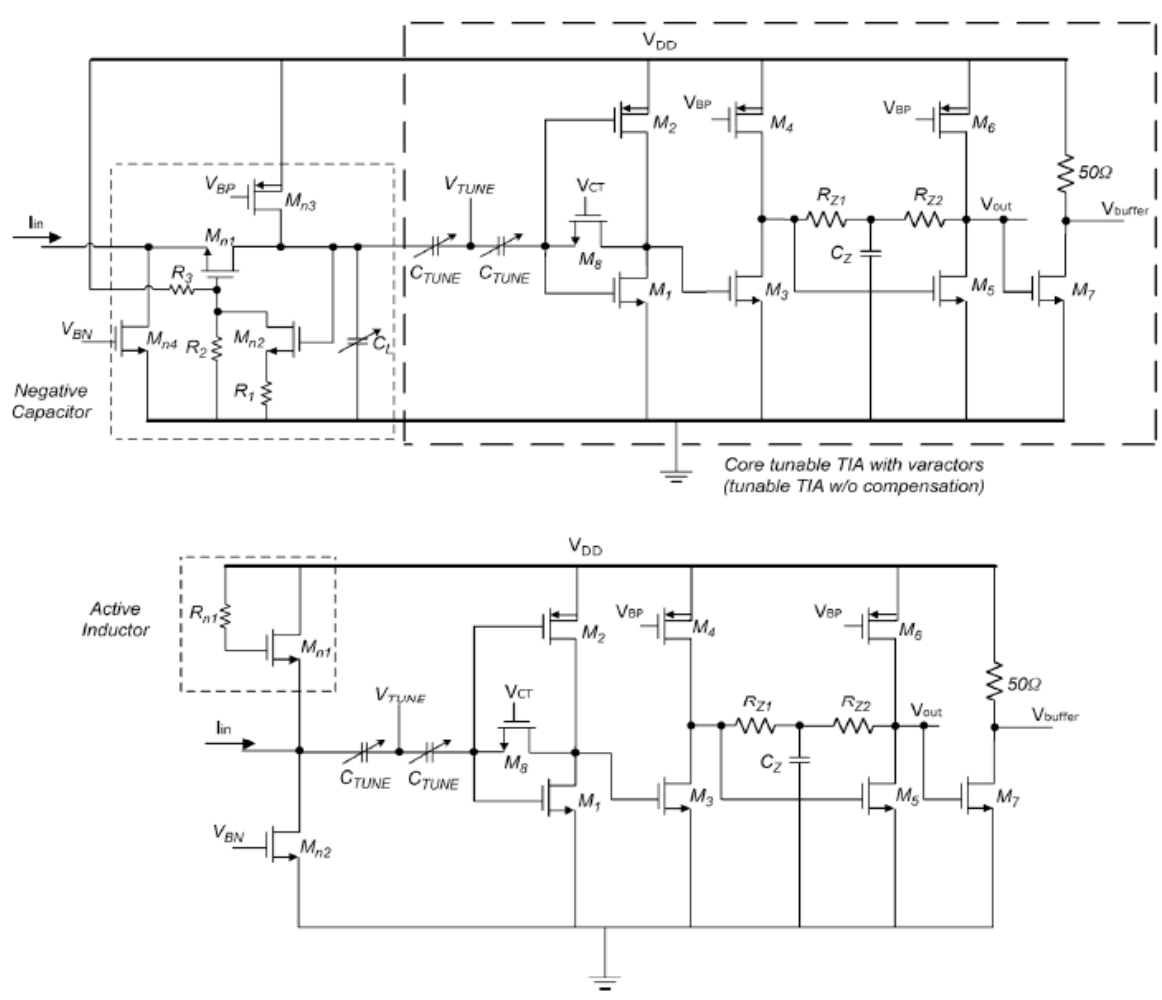

Fig. 12: Amplifier circuit for LBAR with negative capacitor and active inductor cancellation [40]. 
Table 1: Summary of Current Performance of MEMS-Based Oscillator.

\begin{tabular}{|c|c|c|c|c|}
\hline Ref & Resonator & Amplifier Topology & Technology & Performance \\
\hline [29] & $\begin{array}{l}\text { FBAR } \\
\mathrm{Q}_{\mathrm{s}}>1000 \text { for } \\
\mathrm{f}_{\mathrm{s}}=0.5 \sim 7.5 \mathrm{GHz} \\
\mathrm{R}_{\mathrm{x}}=5 \Omega\end{array}$ & $\begin{array}{l}\text { Anti Phase two } \\
\text { Symmetric Differnetial } \\
\text { Circiut }\end{array}$ & $0.13 \mu \mathrm{m}$ CMOS & $\begin{array}{l}\mathrm{f}_{\mathrm{c}}=2.1 \mathrm{GHz} \\
\mathrm{PN}=-143.5 \mathrm{dBc} / \mathrm{Hz} \text { at } 1 \\
\text { MHz offset } \\
\text { Power }=0.6 \mathrm{~mW}\end{array}$ \\
\hline$[33]$ & $\begin{array}{l}\text { Piezoelectric AlN } \\
\text { Contour-Mode } \\
\mathrm{Q}_{\mathrm{s}}=2100 \text { for } \\
\mathrm{f}_{\mathrm{s}}=221.65 \mathrm{MHz} \\
\mathrm{R}_{\mathrm{x}}=35 \Omega\end{array}$ & Pierce Circuit & AMIS $0.5 \mu \mathrm{m}$ CMOS & $\begin{array}{l}\mathrm{f}_{\mathrm{c}}=176 \mathrm{MHz}, 222 \mathrm{MHz} \\
307 \mathrm{MHz} \text { and } 482 \mathrm{MHz} . \\
\mathrm{PN}=-88 \sim-68 \mathrm{dBc} / \mathrm{Hz} \text { at } \\
1 \mathrm{KHz} \text { offset } \\
\text { Power }=10 \mathrm{~mW}\end{array}$ \\
\hline$[35]$ & $\begin{array}{l}\text { Dual-Mode } \\
\text { Piezoelectric AlN } \\
\mathrm{Q}_{\mathrm{s}}=1800 \text { for } \\
\mathrm{f}_{\mathrm{s}}=472.06 \mathrm{MHz} \\
\mathrm{R}_{\mathrm{x}}=123 \Omega \\
\mathrm{Q}_{\mathrm{s}}=600 \text { for } \\
\mathrm{f}_{\mathrm{s}}=1.9411 \mathrm{GHz} \\
\mathrm{R}_{\mathrm{x}}=31 \Omega\end{array}$ & Pierce Circuit & $\begin{array}{l}\text { ON Semiconductor } \\
0.5 \mu \mathrm{m} \text { CMOS }\end{array}$ & $\begin{array}{l}\mathrm{f}_{\mathrm{s}}=472 \mathrm{MHz} \\
\mathrm{PN}=-82 \mathrm{dBc} / \mathrm{Hz} \text { at } 1 \mathrm{kHz} \\
\text { offset } \\
\mathrm{f}_{\mathrm{s}}=1.94 \mathrm{GHz} \\
\mathrm{PN}=-71 \mathrm{dBc} / \mathrm{Hz} \text { at } 1 \mathrm{kHz} \\
\text { offset } \\
\text { Power }=20 \mathrm{~mW}\end{array}$ \\
\hline [36] & $\begin{array}{l}\text { Cantilever MEMS } \\
\text { Resonator } \\
\mathrm{Q}_{\mathrm{s}}=100 \text { for } \\
\mathrm{f}_{\mathrm{s}}=6.4 \mathrm{MHz} \\
\mathrm{R}_{\mathrm{x}}=25.7 \mathrm{M} \Omega\end{array}$ & Pierce Circuit & $\begin{array}{l}\text { AMI Semiconductor } \\
0.35 \mu \mathrm{m} \text { CMOS }\end{array}$ & $\begin{array}{l}\mathrm{f}_{\mathrm{c}}=6.32 \mathrm{MHz} \\
\mathrm{PN}=-94.3 \mathrm{dBc} / \mathrm{Hz} \text { at } 100 \\
\mathrm{kHz} \text { offset } \\
\text { Power }=-\end{array}$ \\
\hline$[38]$ & $\begin{array}{l}\text { IBAR } \\
\mathrm{Q}_{\mathrm{s}}=112000 \text { for } \\
\mathrm{f}_{\mathrm{s}}=5.59 \mathrm{Mhz} \\
\mathrm{R}_{\mathrm{x}}=35 \Omega\end{array}$ & $\begin{array}{l}\text { Transimpedance } \\
\text { Amplifier Circuit }\end{array}$ & $\begin{array}{l}\text { AMI Semiconductor } \\
0.5 \mu \mathrm{m} \text { CMOS }\end{array}$ & $\begin{array}{l}\mathrm{f}_{\mathrm{c}}=6 \mathrm{MHz} \\
\mathrm{PN}=-110 \mathrm{dBc} / \mathrm{Hz} \text { at } \\
1 \mathrm{kHz} \text { offset } \\
\text { Power }=1.9 \mathrm{~mW}\end{array}$ \\
\hline [39] & $\begin{array}{l}\text { Breathe -mode ring } \\
\text { resonator } \\
\mathrm{Q}_{\mathrm{s}}=160000 \\
\mathrm{f}_{\mathrm{s}}=20 \mathrm{MHz} \\
\mathrm{R}_{\mathrm{x}}=65 \mathrm{k} \Omega\end{array}$ & $\begin{array}{l}\text { Transimpedance } \\
\text { Amplifier Circuit }\end{array}$ & $0.35 \mu \mathrm{m}$ CMOS & $\begin{array}{l}\mathrm{f}_{\mathrm{c}}=20 \mathrm{MHz} \\
\mathrm{PN} \text { floor }=-131 \mathrm{dBc} / \mathrm{Hz} \\
\text { Power }=6.9 \mathrm{~mW}\end{array}$ \\
\hline [40] & $\begin{array}{l}\text { LBAR } \\
\mathrm{Q}_{\mathrm{s}}=1400 \text { and } 3000 \\
\mathrm{f}_{\mathrm{s}}=427 \mathrm{MHz} \text { and } \\
541 \mathrm{MHz} \\
\mathrm{R}_{\mathrm{x}}=180 \Omega \text { and } 55 \Omega\end{array}$ & $\begin{array}{l}\text { Transimpedance } \\
\text { Amplifier Circuit }\end{array}$ & $0.18 \mu \mathrm{m}$ CMOS & $\begin{array}{l}\mathrm{f}_{\mathrm{c}}=427 \mathrm{MHz} \text { and } \\
541 \mathrm{MHz} \\
\mathrm{PN}=-82 \mathrm{dBc} / \mathrm{Hz} \text { and }-86 \\
\mathrm{dBc} / \mathrm{Hz} \text { at } 1 \mathrm{kHz} \text { offset } \\
\text { Power }=11.4 \mathrm{~mW}\end{array}$ \\
\hline
\end{tabular}

\section{CONCLUSION}

Table 1 shows the summary of the CMOS oscillator based on MEMS resonator. The CMOS oscillator topologies used are differnetial amplifier circuit, pierce circuit and transimpedance amplifier circuit. The topology chosen normally based on the design criteria to be achieved, like low power and low noise oscillator. Besides that, the $\mathrm{R}_{\mathrm{x}}$ and the insertion losses of the resonator contribute to the suitability of the topology chosen. From the literature made, most commonly used topology for MEMS based oscillator are pierce oscillator circuit topology and TIA circuit topology. Both topologies result in very competitive output interms of phase noise and power consumption. They can be used for either higher or lower $\mathrm{R}_{\mathrm{x}}$. The major difference between both topologies is the number of transistors used. TIA circuit presented in above used more number of transistor compare to pierce circuit. Thus design complexity of the TIA is higher. Pierce circuit is simpler, provides straightforward biasing and easier to design.

The research on replacing the typical RF front-end circuitry with MEMS devices is actively being carried out [32]. MEMS technology allows the combination of a large number of MEMS devices on the same chip. The performance of the current MEMS based 
oscillators are still inferior except for the FBAR MEMS oscillator. The performance of this oscillator not only depended on the MEMS resonator itself, but also on the sustaining circuit chosen.

\section{REFERENCES}

[1] Deparis, Nicolas, Boe, A., Loyez, C., Rolland, N., Rolland, P.-A. "60 GHz UWB-IR transceiver with pulsed-injected locked oscillator." Wireless Technologies, 2007 European Conference on. IEEE, 2007.

[2] Lin, Tsung-Hsien, William J. Kaiser, and Gregory J. Pottie. "Integrated low-power communication system design for wireless sensor networks." Communications Magazine, IEEE 42. 12 (2004): 142-50.

[3] Huang, Qiuting, Orsatti, P., Piazza, F. GSM transceiver front-end circuits in 0.25-\&mu;m CMOS, Solid-State Circuits, IEEE J. 34.3 (1999):292-303.

[4] Burghartz, Joachim N. "Tailoring logic CMOS for RF applications." VLSI Technology, Systems, and Applications, 2001. Proceedings of Technical Papers. 2001 International Symposium on IEEE, 2001: 150-53

[5] Shi, Bo. "Challenges in RF analog integrated circuits, in ASIC, 2001." Proceedings. 4th International Conference, (2001): 800-05.

[6] Hassan, Hassan, Mohab Anis, and Mohamed Elmasry. "Impact of technology scaling on RF CMOS." SOC Conference, (2004): 97-101.

[7] Hiroshi, Iwai. "RF CMOS technology." In Radio Science Conference Proceedings, (2004): 296-8.

[8] Huang, Qiuting, Piazza, F., Orsatti, P., Ohguro, T. "The impact of scaling down to deep submicron on CMOS RF circuits." Solid-State Circuits, IEEE Journal of 33.7 (1998): 102336.

[9] Lin, T-H., Sanchez, H. "Micropower CMOS RF components for distributed wireless sensors." Radio Frequency Integrated Circuits (RFIC) Symposium, IEEE (1998): 157-60.

[10] Steyaert, Michiel SJ, De Muer, B., Leroux, P., Borremans, M., Mertens, K. "Low-voltage low-power CMOS-RF transceiver design." Microwave Theory and Techniques, IEEE Transactions on 50.1 (2002): 281-87.

[11] Nordin, Anis Nurashikin, Karim , J., Zahirul Alam, A.H.M . "A $0.35 \mu \mathrm{m}$ CMOS Pierce Oscillator for MEMS SAW Resonator." Second International Conference on Advances in Electronic Devices and Circuits EDC, (2013): 1-4.

[12] Karim, Jamilah, Nordin, A. N., and Zahirul Alam, A.H.M. "Design of a Pierce Oscillator for CMOS SAW Resonator." 4th International Conference on Computer and Communication Engineering (ICCCE), 2012 International Conference on, IEEE (2012).

[13] Abidi, Asad., Rofougaran, A., Chang, G., Rael, J., Chang, J., Rofougaran, M., Chang, P. The Future of CMOS Wireless Transceivers, IEE International Solid-State Circuits Conference (1997):1996-98.

[14] Steyaert, M., Borremans, M., Janssens, J., De Muer, B., Itoh, N., Craninckx, J., Crols, J. TP 3.3: A Single-Chip CMOS Transceiver for DCS-1800 Wireless Communications, IEE International Solid-State Circuits Conference (1998): 2-3.

[15] Sanduleanu, M. a. T., Vidojkovic, M., Vidojkovic, V., van Roermund, a. H. M., Tasic, a. Receiver Front-End Circuits for Future Generations of Wireless Communications, IEEE Transactions Circuits System II Express Briefs 55.4 (2008):299-303.

[16] Tea, N. H., Milanovi, V., Gaitan, M., Member, S., Zaghloul, M. E., Geist, J. "Hybrid Postprocessing Etching for CMOS-Compatible MEMS, J." Microelectromechanical System 6.4 (1997): 363-72.

[17] Milanovic, V., Gaitan, M. "Design and fabrication of micromachined passive microwave filtering elements in CMOS technology, in International Conference on." Solid State Sensors and Actuators (1997): 1007-10.

[18] Baltes, H., Paul, O., Brand, O. Micromachined thermally based CMOS microsensors, Proceedings of the IEEE 86.8 (1998):1660-78. 
[19] Baltes, H., Brand, O., Hierlemann, A., Lange, D., Hagleitner, C. "CMOS MEMS - present and future." The Fifteenth IEEE International Conference on Micro Electro Mechanical Systems, (2002):459-66.

[20] Nordin, A. N., Zaghloul, M. E. "Modeling and Fabrication of CMOS Surface Acoustic Wave Resonators." Microwave Theory Technology, IEEE Transactions 55.5 (2007):9921001.

[21] Tang, J.V.D., Kasperkovitz, D. High-frequency oscillator design for integrated transceivers, Kluwer Academic Publishers (2003): 748-6221.

[22] Nguyen, N. M., Meyer, R. G. Start-up and frequency stability in high-frequency oscillators. Solid-State Circuits, IEEE J 27.5 (1992):810-20.

[23] Behzad, R.Design of Analog CMOS Integrated Circuits, McGraw Hill (2001).

[24] Poddar, A. K., Rohde, U. L. "Latest Technology, Technological Challenges, and Market Trends for Frequency Generating and Timing Devices [Application Notes]." Microwave Magazine, IEEE 13.6 (2012):120-34.

[25] Packard, H. Application Note - Fundamental of Quartz Oscillator, (1997).

[26] Razavi, B. RF Microelectronics, Prentice Hall (1998).

[27] Odyniec, M. RF and Microwave Oscillator Design, Artech House (2002).

[28] Zuo, C., Van Der Spiegel, J. and Piazza, G. 1.05-GHz CMOS Oscillator Based on Lateral field- excited Piezoelectric AIN contour-mode MEMS resonators, Ultrason. Ferroelect. Freq. Control. IEEE Trans 57.1 (2010): 82-87.

[29] Rai, S. S., Otis, B. P. A 600 $\mu$ W BAW-Tuned Quadrature VCO Using SourcDegenerated Coupling. Solid-State Circuits, IEEE J., 43.1(2008):300-305.

[30] Piazza, G., Stephanou, P., Pisano, A. "AlN Contour-Mode Vibrating RF MEMS for Next Generation Wireless Communications." . Solid-State Circuits Conference, 2006. ESSCIRC 2006. Proceedings of the 32nd European. IEEE, 2006.

[31] Nguyen, C. T. C., Howe, R. T. "An integrated CMOS micromechanical resonator high-Q oscillator." Solid-State Circuits, IEEE J., 34.4(1999):440-55.

[32] Nguyen, C. T. C "Mechanical radio." Spectrum, IEEE J.46.12 (2009): 30-35.

[33] Chengjie, Z., Sinha, N., Van der Spiegel, J., Piazza, G. Multifrequency Pierce Oscillators Based on Piezoelectric AlN Contour-Mode MEMS Technology. Microelectromechanical System. Journal; , 19.3(2010):570-80.

[34] Piazza, G., Stephanou, P. J., Pisano, A. P. Piezoelectric Aluminum Nitride Vibrating Contour-Mode MEMS Resonators. Microelectromechanical System. Journal, 15.6(2006):1406-18.

[35] Chengjie, Z., Van der Spiegel, J., Piazza, G. Dual-Mode Resonator and Switchless Reconfigurable Oscillator Based on Piezoelectric AlN MEMS Technology. Electron Devices, IEEE Trans., 58.10(2011):3599-603.

[36] Verd, J., Uranga, A., Abadal, G., Teva, J. L., Torres, F., Lopez, J. L., Perez-Murano, E., Esteve, J., Barniol, N. Monolithic CMOS MEMS Oscillator Circuit for Sensing in the Attogram Range. Electron Device Lett. IEEE, 29.2(2008):146-48.

[37] Sundaresan, K., Ho, G. K., Pourkamali, S., Ayazi, F. Bulk Acoustic Resonator Reference Oscillators. IEEE J. Solid-State Circuits, 42.6 (2007):1425-34.

[38] Ho, G. K., Sundaresan, K., Pourkamali, S., Ayazi, F. Micromechanical IBARs: Tunable High-Q Resonators for Temperature-Compensated Reference Oscillators. Microelectromechanical System. Journal, 19.3 (2010):503-15.

[39] Seth, S., Wang, S., Kenny, T., Murmann, B. A-131-dBc/Hz, 20-MHz MEMS oscillator with a 6.9-mW, 69-kohm, gain-tunable CMOS TIA. ESSCIRC (ESSCIRC), 2012 Proceedings, (2012):249-252.

[40] Lavasani, H. M., Wanling, P., Harrington, B. P., Abdolvand, R., Ayazi, F. Electronic Temperature Compensation of Lateral Bulk Acoustic Resonator Reference Oscillators Using Enhanced Series Tuning Technique. Solid-State Circuits, IEEE J., 47.6 (2012):1381-93.

[41] Lavasani, H. M., Wanling, P., Harrington, B., Abdolvand, R., Ayazi, F. A 76 dB, 1.7 GHz $0.18 \mu \mathrm{m}$ CMOS Tunable TIA Using Broadband Current Pre-Amplifier for High Frequency Lateral MEMS Oscillators. Solid-State Circuits, IEEE J., 46.1(2011):224-35. 